\title{
Foraging distance affects reproductive success in Magellanic penguins
}

\author{
P. Dee Boersma*, Ginger A. Rebstock \\ University of Washington, Department of Biology, Box 351800, Seattle, Washington 98195-1800, USA
}

\begin{abstract}
Foraging distance affects reproductive success and other demographic parameters in seabirds and pinnipeds. We tracked breeding Magellanic penguins Spheniscus magellanicus at Punta Tombo, Argentina using satellite transmitters from 1996 to 2006 ( $\mathrm{n}=148$ males, 57 females) to investigate the variability in foraging distance and its effects on reproductive success. The time a penguin was away from its nest predicted the distance it swam during all stages of the breeding season $(p<0.005)$; this relationship was linear during incubation and nonlinear during chick rearing. During incubation, penguins went $1.0 \mathrm{~km}$ farther from the colony for every additional hour they were away from the nest, and the distance penguins traveled predicted the mean colony reproductive success. When chicks were $>30 \mathrm{~d}$ old, the probability of fledging 2 chicks was highest when penguins went less than $70 \mathrm{~km}$ from their nests. Penguins that went between 70 and $180 \mathrm{~km}$ from their nests were most likely to raise one chick, and the probability of losing both chicks increased with trip distance. Females and males made trips of similar distance. Foraging-trip distance varied within breeding season $(\mathrm{p}<0.005)$. Penguins went farthest during incubation $(411 \pm 11.8 \mathrm{~km})$, and stayed closest $(61 \pm 3.9 \mathrm{~km})$ when chicks were $<30 \mathrm{~d}$ old, requiring parents to guard them. When chicks were older, adults traveled $111 \pm 5.0 \mathrm{~km}$. Mean foraging-trip distance varied among years $(\mathrm{p}<0.005)$ by factors of 1.5 to 1.8 , and trips by an individual penguin varied by a factor of 22 .
\end{abstract}

KEY WORDS: Spheniscus magellanicus - Magellanic penguin · Foraging-trip distance - Variability · Reproductive success $\cdot$ Satellite tracking $\cdot$ Argos $\cdot$ Argentina

\section{INTRODUCTION}

Oceanographic conditions vary from year to year, affecting the foraging locations and breeding success of marine central-place foragers, such as seabirds and pinnipeds, that feed at sea but breed on land (Boyd et al. 1994, Kitaysky et al. 2000, Sydeman et al. 2001, Davoren \& Montevecchi 2003). Foraging locations at sea, particularly distance to food, influence offspring feeding frequency (Pinaud et al. 2005), reproductive success (Inchausti et al. 2003), and adult energy balance (Shaffer et al. 2003). How central-place foragers use the ocean affects not only their breeding parameters, but also their conservation, because of increasing conflicts between human activities and wildlife (Boersma 2008). Our knowledge of where seabirds and pinnipeds forage has increased during the last decade because of remote-tracking devices (e.g. Burger \&
Shaffer 2008). In many cases, we know mean foragingtrip distances, but little about how distances and foraging areas vary. Quantifying the variability in trip distance among years is necessary for a variety of reasons including understanding species' energy needs, reproductive success, recruitment, population dynamics, and determining ocean zoning and locations of protected areas for management and conservation.

For central-place foragers, distance to foraging areas is often related to trip duration and the frequency of offspring feeding (Shaffer et al. 2003, Boersma et al. 2007). Many seabirds and pinnipeds feed at particular oceanographic features (Hunt et al. 1999, Boersma et al. in press), and flying or swimming from breeding sites to the foraging areas make up a large percentage of the trip duration. Boersma et al. (in press) found a nonlinear relationship between trip distance and duration, with penguins spending more time in foraging 
areas farther from the colony. If foraging trips take longer, offspring will be fed less frequently, resulting in slower growth rates and lower weights at fledging or weaning (Kitaysky et al. 2000, Davoren \& Montevecchi 2003). Longer travel distances also require increased energy expenditure that may affect adult body condition (Arnould et al. 1996) and the balance between food assimilated by the adult and that delivered to offspring (Weimerskirch et al. 1994, Ropert-Coudert et al. 2004). In the case of seabirds that share incubation and provisioning duties, long trip distances and durations may also affect the fasting mate's condition, eventually causing abandonment of the nest (Yorio \& Boersma 1994, Numata et al. 2000, Tveraa \& Christensen 2002).

In some seabird species, males and females have different foraging strategies during the breeding season (Clarke et al. 1998, González-Solís et al. 2008). This is often linked to sexual size dimorphism, but also occurs in species with males and females of similar size (Lewis et al. 2002). Male Magellanic penguins are slightly larger than females and are at sea a few weeks earlier during incubation (Boersma et al. 1990). Either of these differences may cause males and females to adopt different foraging strategies.

Trip distance often varies across the breeding season, reflecting different constraints (Weimerskirch et al. 1993, Guinet et al. 1997, Beauplet et al. 2004, Lescroël \& Bost 2005, Phalan et al. 2007). Older chicks have greater food needs and greater storage capacity than younger chicks (Walker \& Boersma 2003) which may both require and allow adults to go farther to forage when chicks are older. Seabirds can go farthest during incubation when there are no chicks to feed; they need to stay closest to the colony when chicks are small, have limited storage capacity (small stomachs and limited energy reserves), and require the attendance of a parent for protection and thermoregulation. Adults may go intermediate distances when chicks are larger and have increased storage capacity and energy needs. Additionally, prey distribution may change during the breeding season, resulting in changes in foraging-trip distance (Humphreys et al. 2006).

Interannual changes in prey distribution or availability may also cause foraging-trip distance to vary (Boyd et al. 1994, Sydeman et al. 2001, Inchausti et al. 2003). Longer foraging trips in years of low prey availability may cause increased investment in reproduction by adults (Boyd et al. 1994) and decreases in offspring growth rates (Davoren \& Montevecchi 2003, Pinaud et al. 2005) and reproductive success (Inchausti et al. 2003). Climate fluctuations may affect species differently, depending on prey and foraging strategies (Kitaysky et al. 2000).

We present foraging-trip data from 11 years of satellite tracking the at-sea locations of over 200 breeding
Magellanic penguins Spheniscus magellanicus at Punta Tombo, Argentina. Using our large dataset we quantified the relationships between trip distance and duration, and between trip distance and reproductive success. We also tested whether foraging-trip distance differed between males and females, and quantified variability in trip distances within and among breeding seasons.

\section{MATERIALS AND METHODS}

Magellanic penguins breed at mainland and island colonies in Argentina, Chile and the Falkland (Malvinas) Islands (Williams 1995). They eat primarily small pelagic fish, hake Merluccius hubbsi, and squid (Williams 1995) that are often associated with oceanographic frontal systems (Hansen et al. 2001, Acha et al. 2004). We divided breeding into 3 stages: (1) incubation, when mates alternate long incubation periods with long-duration foraging trips, generally midOctober to late November; (2) early-chick rearing, when mates alternate every couple of days between attending the chicks and foraging, late November to late December; and (3) late-chick rearing, when both adults forage simultaneously and leave the chicks unattended, from late December until fledging in January or February (Boersma et al. 1990). During incubation, males generally take their longest foraging trip after egg laying, and females after the males return to relieve them. Males are typically at sea during October and females during November, with some overlap in late October and early November. (Boersma et al. 1990). We checked nests daily until both chicks hatched, and used chick age ( $<30 \mathrm{~d}$ or $>30 \mathrm{~d}$ ) to separate early-chick and late-chick period tracks. Year refers to the calendar year of the beginning of the breeding season, e.g. 2006 is the 2006-2007 season.

Satellite tracking. We tracked Magellanic penguins at Punta Tombo, Argentina $\left(44^{\circ} 2.7^{\prime} \mathrm{S}, 65^{\circ} 13.4^{\prime} \mathrm{W}\right)$ using satellite transmitters and the Argos system (Argos 2006). From the late-chick stage of 1996 through the 2006 season, we attached transmitters to 148 adult males and 57 adult females in a total of 268 deployments (Table 1). We tracked 49 penguins more than once (43 males and 6 females) but in different years. For 52 penguins transmitters did not start until the penguin was far at sea, or failed prematurely, resulting in incomplete trips that we did not use. We attached the devices to feathers with fast-setting epoxy or tape (Wilson \& Wilson 1989) and epoxy. We reduced drag on the devices by centering them low (6.6 \pm $1.5 \mathrm{~cm}$ above the uropygial gland, $\mathrm{n}=219$ ) on the penguin's back (Bannasch et al. 1994) and positioning feathers over the leading edge. 
Table 1. Spheniscus magellanicus. Satellite transmitters deployed $(\mathrm{n}=268)$ on Magellanic penguins at Punta Tombo from the 1996 breeding season through the 2006 season. Numbers in parentheses in 'No. males' and 'No. females' columns represent the deployments $(n=216)$ with nearly complete trips, which were used to calculate trip distances. Inc $=$ incubation; EC $=$ early chick; LC = late chick. See 'Materials and methods' for definitions. Deployment dates are dates transmitters were attached; transmitters were left on for 30 to $90 \mathrm{~d}$. Mean weight is at time of deployment

\begin{tabular}{|c|c|c|c|c|c|c|c|}
\hline Year & Stage & $\begin{array}{l}\text { Deployment } \\
\text { dates }\end{array}$ & No. males & $\begin{array}{l}\text { Mean weight } \\
\pm \text { SE }(\mathrm{kg})\end{array}$ & No. females & $\begin{array}{l}\text { Mean weight } \\
\pm \mathrm{SE}(\mathrm{kg})\end{array}$ & $\begin{array}{c}\text { Transmitter } \\
\text { type(s) }\end{array}$ \\
\hline 1996 & $\mathrm{LC}$ & 15 Dec 1996-18 Jan 1997 & $5(3)$ & $4.44 \pm 0.207$ & 0 & & ST-10 \\
\hline \multirow[t]{2}{*}{1997} & Inc & 13-19 Oct 1997 & $3(2)$ & $4.11 \pm 0.176$ & $3(3)$ & $3.76 \pm 0.185$ & ST-10 \\
\hline & $\mathrm{LC}$ & 23-31 Dec 1997 & $5(5)$ & $4.89 \pm 0.231$ & 0 & & ST-10 \\
\hline \multirow[t]{3}{*}{1998} & Inc & $5-18$ Oct 1998 & $4(3)$ & $4.30 \pm 0.120$ & $4(2)$ & $3.36 \pm 0.063$ & ST-10 \\
\hline & $\mathrm{EC}$ & 8-17 Nov 1998 & $6(6)$ & $4.44 \pm 0.114$ & $6(6)$ & $4.41 \pm 0.158$ & ST-10 \\
\hline & $\mathrm{LC}$ & 26 Dec 1998-12 Jan 1999 & $6(5)$ & $4.24 \pm 0.159$ & $5(5)$ & $3.44 \pm 0.070$ & ST-10 \\
\hline \multirow[t]{3}{*}{1999} & Inc & $9-22$ Oct 1999 & $5(4)$ & $4.04 \pm 0.165$ & $5(1)$ & $3.13 \pm 0.078$ & ST-10 \\
\hline & $\mathrm{EC}$ & 22-27 Nov 1999 & $5(3)$ & $4.17 \pm 0.199$ & $5(3)$ & $3.64 \pm 0.173$ & ST-10 \\
\hline & $\mathrm{LC}$ & 5-18 Jan 2000 & $4(3)$ & $4.33 \pm 0.198$ & $2(2)$ & $3.80 \pm 0.400$ & ST-10 \\
\hline \multirow[t]{3}{*}{2000} & Inc & $7-28$ Oct 2000 & $17(13)$ & $4.00 \pm 0.110$ & $6(0)$ & $3.63 \pm 0.162$ & ST-10 \& Kiwisat \\
\hline & $\mathrm{EC}$ & 27 Nov-9 Dec 2000 & $6(4)$ & $3.88 \pm 0.154$ & $6(5)$ & $3.47 \pm 0.119$ & ST -10 \\
\hline & $\mathrm{LC}$ & 5-13 Jan 2001 & $7(6)$ & $4.44 \pm 0.118$ & $5(4)$ & $3.50 \pm 0.085$ & ST-10 \\
\hline \multirow[t]{3}{*}{2001} & Inc & $8-19$ Oct 2001 & $6(5)$ & $4.08 \pm 0.096$ & $6(2)$ & $3.27 \pm 0.129$ & ST-10 \\
\hline & $\mathrm{EC}$ & 13-19 Nov 2001 & $4(4)$ & $4.43 \pm 0.138$ & $4(4)$ & $4.18 \pm 0.165$ & ST-10 \\
\hline & $\mathrm{LC}$ & 26-31 Dec 2001 & $8(8)$ & $4.47 \pm 0.182$ & $6(6)$ & $3.49 \pm 0.260$ & ST-10 \\
\hline \multirow[t]{2}{*}{2002} & Inc & 15-25 Oct 2002 & $12(4)$ & $4.07 \pm 0.130$ & 0 & & ST-10 \\
\hline & $\mathrm{LC}$ & 26 Dec 2002-2 Jan 2003 & $12(12)$ & $4.33 \pm 0.096$ & 0 & & ST-10 \\
\hline \multirow[t]{2}{*}{2003} & Inc & $9-15$ Oct 2003 & $10(9)$ & $4.26 \pm 0.070$ & 0 & & ST-10 \\
\hline & $\mathrm{LC}$ & 21 Dec $2003-1$ Jan 2004 & $7(7)$ & $4.44 \pm 0.189$ & 0 & & ST-20 \& ST-10 \\
\hline \multirow[t]{2}{*}{2004} & Inc & $3-10$ Oct 2004 & $12(9)$ & $4.24 \pm 0.069$ & 0 & & ST-20 \& ST-10 \\
\hline & $\mathrm{LC}$ & 27 Dec $2004-8$ Jan 2005 & $13(12)$ & $4.38 \pm 0.059$ & 0 & & ST-20 \& ST-10 \\
\hline \multirow[t]{2}{*}{2005} & Inc & $8-13$ Oct 2005 & $12(11)$ & $4.24 \pm 0.091$ & 0 & & ST- 20 \\
\hline & $\mathrm{LC}$ & 26 Dec 2005-7 Jan 2006 & $12(12)$ & $4.53 \pm 0.107$ & 0 & & ST-20 \\
\hline \multirow[t]{2}{*}{2006} & Inc & $9-20$ Oct 2006 & $12(12)$ & $4.13 \pm 0.071$ & 0 & & ST-20 \\
\hline & $\mathrm{LC}$ & $19-30$ Dec 2006 & $12(11)$ & $4.74 \pm 0.127$ & 0 & & ST-20 \\
\hline Totals & & & $205(173)$ & $4.30 \pm 0.028$ & $63(43)$ & $3.61 \pm 0.058$ & \\
\hline
\end{tabular}

We used 3 types of transmitters (Table 1): ST-10s and ST-20s transmitted every 45 s every day, Kiwisat transmitters were programmed to transmit every $60 \mathrm{~s}$ for $12 \mathrm{~h}$ out of each $48 \mathrm{~h}$ (12 h on:36 h off). ST-20 and Kiwisat transmitters were higher power $(0.5 \mathrm{~W})$ than ST-10s $(0.25 \mathrm{~W})$ and provided more frequent and higher-quality locations (authors' unpubl. data).

Track processing. We used only Argos locations calculated from 4 or more messages received during each satellite pass (location class 0-3). Argos estimates 1 SD of errors in latitude and longitude of Class 1 to 3 locations to be within $1000 \mathrm{~m}$, while Class 0 locations have no estimate of error (Argos 2006). We applied 4 filters to the data (authors unpubl.). The first filter removed locations closer together than $45 \mathrm{~min}$, to make the samples more evenly spaced. The second and third filters were the speed filters of Austin et al. (2003) and McConnell et al. (1992). The 4 th filter removed locations that were far off the penguin's track, but were not rejected by the speed filters because they were far apart in time (authors' unpubl.).

We calculated trip distance as the straight-line distance from Punta Tombo to the farthest point of each trip (Boersma et al. in press). This is less than the total distance traveled by the penguins, because they often make looping trips with meanders. During incubation, we used the longest trip recorded that began after the first egg was laid for each bird. In 24 cases, we used incomplete trips (those in which transmission began or ended at sea but close to the colony relative to the trip distance; $13.2 \pm 12.6 \%$ mean $\pm \mathrm{SD}$ ) for distance calculations but not for estimating trip duration. During the chick-rearing periods, we generally recorded more than one trip per penguin. We defined a trip as at least 3 consecutive points that were at least $5 \mathrm{~km}$ from Punta Tombo with at least one point preceding and following within $5 \mathrm{~km}$ of Punta Tombo (Boersma et al. in press). We used nest attendance data to determine when penguins returned to the colony, and if returns were not recorded in the Argos data, we used the trips to calculate distance but not duration.

For each stage of the breeding season, we calculated the maximum and mean trip distances for each penguin in each year. No penguin was tracked in more than one period in the same year; hence we used one value per individual except where the same penguin was tracked in multiple years $(n=32)$. For incubation, maximum and mean trip distances were the same since we used one trip per penguin (per year). 
Foraging trip distance and duration. We previously reported a positive relationship between trip distance and duration for female penguins at Punta Tombo (Boersma et al. 2007). Here we refined the relationships using both males and females. The trip distances differed from those used in the earlier paper (Boersma et al. 2007), because we used only Argos locations of Class 1 to 3 in the earlier regressions; in the present analysis we also included Class 0 and filtered all 4 location classes. Retention of Class-0 locations resulted in more trips and sometimes longer trips in the current analysis.

Graphs of trip distance as a function of duration by individual penguins during the chick-rearing stages indicated that slopes and intercepts might differ by individual. We fitted mixed-effects models (randomintercept models, allowing the intercept to vary among penguins as in the previous study) and mixed-effects random-coefficient models (allowing both intercept and slope to vary among penguins) (Rabe-Hesketh \& Skrondal 2005). We included duration squared to test for nonlinearity, since some curves appeared to flatten out for longer trips. We included year, sex, and the interaction between sex and duration as factors.

For incubation, we had a maximum of 3 trips (in different years) for any penguin. We calculated robust SEs, with degrees of freedom equal to the number of individual penguins, to account for the lack of independence when the same bird was tracked in more than one year (Long \& Freese 2006). For incubation, we only used the higher-power ST-20 transmitters, deployed in 2004-2006 on males only, because we had few complete incubation trips from ST-10 transmitters and we could not estimate trip duration for the intermittent Kiwisat transmitters. For chick-rearing stages, we ran regressions for the years 1998 to 2001, when we tracked males and females, and all years for the latechick stage (1996 to 2006).

Foraging trip distance and reproductive success. We measured reproductive success yearly in 2 areas within the colony separated by about $320 \mathrm{~m}$. We checked all nests (mean $\pm \mathrm{SD}=173.5 \pm 36.4$ nests with eggs per year) within the 2 study areas every 1 to $10 \mathrm{~d}$ from prior to egg laying until fledging. We counted chicks as fledged if they were last seen after 10 January, weighed $\geq 1800 \mathrm{~g}$, and had not lost weight during the last few measurements (Boersma et al. 1990). Reproductive success was calculated as the number of chicks fledged per nest with eggs, with a maximum of 2 . We tested the effect of mean distance from the colony that penguins swam during incubation and the late-chick stage on mean reproductive success using multiple linear regression. We did not test for an effect when chicks were $<30 \mathrm{~d}$ old because we only had 4 years of data. We included precipitation as a covariate because heavy rain can cause nests to flood or collapse, killing embryos and small chicks (Boersma et al. 2004, Boersma 2008). We measured rainfall daily with an on-site rain gauge, except in 2005, when we used data collected at the La Regina Estancia, about $25 \mathrm{~km}$ from Punta Tombo. We used total rainfall between 16 October and 15 December, when eggs and chicks are most vulnerable to weather. The Estancia data for 2005 covered 1 October to 31 December and although this was a longer period, the total rainfall in 2005 was lower than what affected reproductive success in the other years (Boersma 2008). We removed the 3 years with heaviest rainfall from 16 October to 15 December ( $>50 \mathrm{~mm}$ ) and regressed reproductive success on mean trip distance during incubation and late-chick stages.

We also compared the number of chicks fledged by each penguin that carried a transmitter during each stage of the breeding season with the mean trip distance for that penguin using a multinomial logistic regression. We used only penguins that still had 2 chicks when we attached the transmitters (28 of 33 penguins when chicks were small and 79 of 100 penguins when chicks were older). All years were combined and robust SEs were calculated to account for the lack of independence in trips by the same penguin. Following the regression, we modeled the predicted probability of each outcome for each mean distance (Long \& Freese 2006).

We used an index based on the first principal component of bill, wing, and foot measurements (Yorio \& Boersma 1994, Hood et al. 1998) to evaluate the body condition of 3 females that made unusually long trips during late-chick stages of 1998 and 2001. Because of small sample sizes in 1998 and 2001, we used all females weighed and measured between 16 December and 15 January 1983 to 2006 to develop the index ( $\mathrm{n}=$ 473). We also compared an egg-volume index (length $\times$ width $\left.^{2}\right)$ for 2 of the females to the means for $1998(\mathrm{n}=$ 538 1st eggs, 508 2nd eggs), as lower clutch volumes reflect poor female body condition at egg laying (Moreno et al. 2002). Egg size has little influence on nesting success but it does reflect parental quality in Magellanic penguins (Reid \& Boersma 1990).

Variation between sexes, within and among seasons. We used multiple regression to test for effects of stage of the breeding season, year, and sex on trip distances. We included year as a categorical factor rather than a continuous variable because we expected interannual differences in prey availability but not necessarily a linear trend. In addition to regressions for 1996 to 2006, we ran separate tests for 1997 to 2001, the only years in which we tracked females (Table 1). We also ran regressions for 1998 to 2001, the only years in which we tracked during the early-chick stage (both sexes). We also included start date of incubation trip instead of sex in one set of regressions because date may be more important than sex, and variability in trip 
timing within males and females may mask the effects of date.

Regression models were run in Stata 9.2 (StataCorp LP). Examination of the residuals did not indicate problems with any of the regression fits. Means are presented $\pm 1 \mathrm{SE}$.

\section{RESULTS}

\section{Foraging-trip distance and duration}

Trip distance was positively correlated with trip duration, although the details of the relationships varied over the breeding season (Table 2). Trip distance depended linearly on duration during incubation (26 trips by 23 penguins, males only, $F_{3,22}=23.65, \mathrm{p}<0.005, \mathrm{R}^{2}=$ 0.74; coefficient for duration: $t=8.01, \mathrm{p}<0.005$ ) but not on year ( $p=0.41$ and 0.75$)$. Duration squared was not significant $(p=0.84)$, indicating the relationship was linear. Penguins went $1.0 \pm 0.13 \mathrm{~km}$ farther from the colony for every hour they were away from the nest.

Distance depended nonlinearly on duration when penguins had small chicks (152 trips by 33 penguins): both duration $(Z=16.0, \mathrm{p}<0.005)$ and duration squared $(Z=-7.19, \mathrm{p}<0.005)$ were significant (Table 2$)$. The relationship between distance and duration also varied significantly with year $(\mathrm{p}<0.005)$ : slopes were steeper in 2000 and 2001 when penguins went farther from the colony than in 1998 and 1999 when they stayed closer to their nests. Penguins generally swam farther in 2000 and 2001 than in the first 2 years, but trip durations were not proportionately longer. Sex $(Z=-1.27, \mathrm{p}=$ $0.20)$ and the interaction between sex and duration $(Z=1.28, \mathrm{p}=0.20)$ were not significant. Trips by different penguins had similar slopes: the random-coefficient model was not significantly better than the random-intercept model (likelihood-ratio test: LR $\chi^{2}(2)=$ $1.82, \mathrm{p}=0.4)$. Moreover, correcting for the conservative nature of the likelihood-ratio test (Rabe-Hesketh \& Skrondal 2005) gave similar results. Results of a linear

Table 2. Spheniscus magellanicus. Relationship between foraging-trip distance and duration during 3 stages of the breeding season. Relationships were nonlinear if duration squared was included in the best model. Only males were used in the regression for incubation. Slopes by individual penguin could not be tested for incubation because we used only 1 trip per penguin (per year). N/A: not applicable

\begin{tabular}{|lccc|}
\hline & Incubation & Early chick & Late chick \\
\hline Linear & Yes & No & No \\
Years differ & No & Yes & No \\
Sexes differ & N/A & No & No \\
Slopes differ & N/A & No & Yes \\
\hline
\end{tabular}

regression run without duration squared were similar to those of Boersma et al. (2007), after excluding a female that went almost $300 \mathrm{~km}$ after her chicks died: in both analyses the slope was $0.87 \pm 0.07$.

The non-linear relationship between distance and duration of penguin foraging trips was also apparent when penguins had large chicks (191 trips by 37 penguins): duration $(Z=15.84, \mathrm{p}<0.005)$ and duration squared $(Z=$ $-7.36, \mathrm{p}<0.005$ ) were significant (Table 2). The relationship between trip distance and duration did not depend on year ( $p=0.15$ to 0.70$)$, sex $(p=0.93)$, or the interaction between sex and duration $(p=0.69)$. However, individual penguins had different slopes $\left(\operatorname{LR} \chi^{2}(2)=61.33\right.$, $p<$ $0.005)$. Results from a linear regression were similar to those reported in Boersma et al. (2007) for females: in both cases, penguins went $0.87 \pm 0.04 \mathrm{~km}$ farther from the colony for each hour they were gone.

\section{Foraging-trip distance and reproductive success}

As foraging-trip distance increased, mean reproductive success of the colony decreased. Rainfall between 16 October and 15 December negatively affected reproductive success $\left(F_{1,8}=33.1, \mathrm{p}=0.0004\right.$, adjusted $\mathrm{R}^{2}=0.78$, RMSE $=0.136$ ) (Fig. 1). Adding mean trip distance during incubation as a covariate improved the fit $\left(F_{2,7}=22.96, \mathrm{p}=0.0008\right.$, adjusted $\mathrm{R}^{2}=0.83, \mathrm{RMSE}=$ $0.120)$. However, adding mean trip distance during late chick did not improve the fit (rain only: adjusted $\mathrm{R}^{2}=0.77, \mathrm{RMSE}=0.147$; rain + trip distance: adjusted $\mathrm{R}^{2}=0.75, \mathrm{RMSE}=0.152$ ). With the 3 years of heaviest rainfall removed, reproductive success depended on

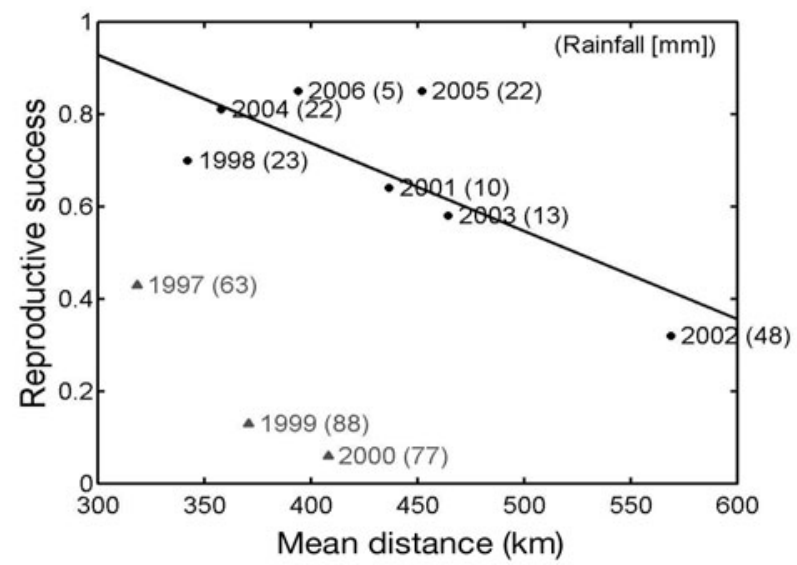

Fig. 1. Spheniscus magellanicus. Mean reproductive success (number of chicks fledged per nest with eggs) in 2 areas of the colony as a function of the mean distance penguins traveled from the colony during incubation. Points are labeled with year and total rainfall (parentheses, in $\mathrm{mm}$ ) between 16 October and 15 December. $(\bullet)$ years with $<50 \mathrm{~mm}$ rain; $(\Delta)>50 \mathrm{~mm}$ rain; (Line) least-squares regression excluding 3 years with $>50 \mathrm{~mm}$ rain (reproductive success $=1.5-0.002 \times$ mean distance; adjusted $\mathrm{R}^{2}=0.51$ ) 
trip distance during incubation $\left(F_{1,5}=7.28, \mathrm{p}=0.04\right.$, adjusted $\mathrm{R}^{2}=0.51, \mathrm{n}=7$ ) (Fig. 1), but not during late chick $\left(F_{1,6}<0.1, \mathrm{p}=0.96, \mathrm{n}=8\right)$.

Foraging-trip distance also predicted individuals' reproductive success (Fig. 2). The multinomial logistic regression of number of chicks fledged on mean trip distance for transmitter-equipped birds with chicks older than $30 \mathrm{~d}$ was significant (Wald $\chi^{2}=5.96, \mathrm{p}=$ $0.015)$. The probability of fledging 2 chicks was high $(>0.5)$ for penguins that made the shortest trips $(<70 \mathrm{~km})$ and decreased with increasing distance to $<0.01$ (Fig. 2). The probability of fledging zero chicks was low ( 0.01) for birds making very short trips but increased with increasing distance to $\sim 0.8$. The probability of fledging one chick peaked at intermediate foraging distances ( $~ 70$ to $180 \mathrm{~km})$ and was lower at short and long distances. There was no relationship between number of chicks fledged and mean trip distance during incubation (Wald $\chi^{2}=0.69, \mathrm{p}=0.71$ ) or when chicks were small (Wald $\chi^{2}=1.45, \mathrm{p}=0.48$ ).

\section{Variation between sexes}

Males and females traveled similar distances during incubation (all years and 1997 to 2001: $\mathrm{p} \geq 0.46$ ) (Fig. 3). Foraging-trip distance was not related to trip start date $(p \geq 0.36)$, suggesting the prey distribution was similar throughout incubation. When chicks were small, males and females also traveled similar distances (mean and maximum distance: $\mathrm{p} \geq 0.67$ ). When chicks were $>30 \mathrm{~d}$ old, maximum but not mean distance was greater for females than for males (all years

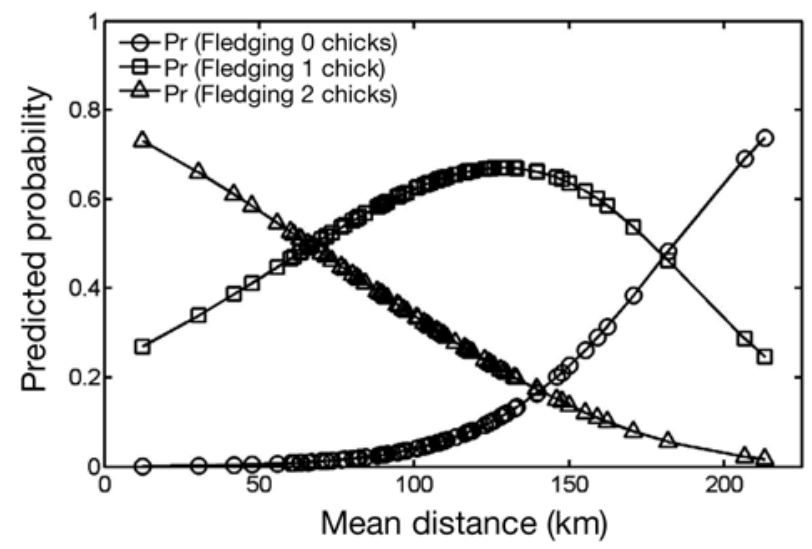

Fig. 2. Spheniscus magellanicus. Predicted probability of Magellanic penguin fledging success $(0,1$, or 2 chicks) calculated from the multinomial regression of chicks fledged against mean foraging-trip distance during the late-chick stage $(n=78)$. Predicted fledging probabilities are plotted against actual mean distances. One female that traveled $>300 \mathrm{~km}$ was excluded. Each penguin tracked had 2 chicks $30 \mathrm{~d}$ of age or older when the transmitters were attached in late December or early January 1996-2007

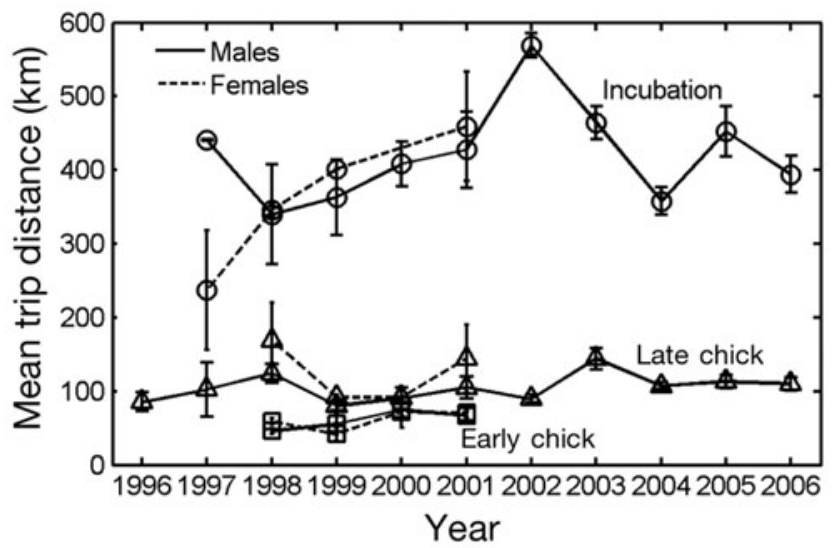

Fig. 3. Spheniscus magellanicus. Mean trip distance by stage of the breeding season, year, and sex for Magellanic penguins breeding at Punta Tombo, Argentina. Error bars are 1 SE. See Table 1 for sample sizes. (O) incubation; $(\square)$ early chick; $(\Delta)$ late chick; $(-)$ males; (---) females. Distance varied by stage and year, but not sex

and 1998 to 2001, maximum distance: $\mathrm{p}=0.03$ and 0.04; mean distance: $\mathrm{p} \geq 0.21$ ).

The difference between the sexes in maximum foraging-trip distance during late chick was driven by 3 females (2 in 1998, 1 in 2001) that took trips of 275, 307, and $372 \mathrm{~km}$ with durations of 23, 19.5, and $18.2 \mathrm{~d}$, respectively (see Fig. 6f). Excluding these 3 trips there were no significant differences between the sexes, nor was the interaction between sex and breeding stage significant (Table 3). The mean trip duration for late chick, excluding the 3 females, was $2.9 \mathrm{~d}$; the 3 females made trips 6 times the mean duration. The longest trip by any other penguin was $10.8 \mathrm{~d}$. The female that made an unusually long trip in 2001 of $18.2 \mathrm{~d}$ had the lowest body condition index in our dataset $(n=473)$. The 2 females that made unusually long trips in 1998 were also in poor condition (negative index), but did not have lower index values than other females we tracked. However, they both laid at least one small egg (1st eggs: 219.9 and $232.1 \mathrm{~cm}^{3}$; 2 nd eggs: 213.0 and $218.0 \mathrm{~cm}^{3}$ ) compared to the mean egg size for 1998 (1st eggs: $231.7 \pm 0.9 \mathrm{~cm}^{3}, \mathrm{n}=538 ;$ 2nd eggs: $228.8 \pm$ $1.0 \mathrm{~cm}^{3}, \mathrm{n}=506$ ), indicating that they were in poor body condition when they laid eggs. All 3 females returned to their nests before the end of the season, and 2 of the 3 bred in subsequent years. Males were seen at the nests 2 to 15 times while the females were at sea and were able to compensate in part for the females' absence, as 2 of the 3 pairs fledged one chick. The third pair had one chick that was still alive but weighed $<1.8 \mathrm{~kg}$ (our criterion for fledging) when last seen on 3 February, $>2$ wk after the return of the female. A few males made trips $>275 \mathrm{~km}$ from the colony, but none made trips with duration $>11 \mathrm{~d}$ during chick rearing. 
Table 3. Spheniscus magellanicus. Multiple regressions of maximum and mean trip distance on stage of the breeding season, year (as a categorical variable), sex, and the interaction between sex and stage. Foraging-trip distance depended on stage of the breeding season and year. The significant coefficients for sex (for maximum distance only) and the interaction between sex and stage were driven by 3 females that made anomalous trips (see 'Results'). Statistics for sex and the interaction excluding those 3 females are also shown. Inc: incubation; LC: late chick; EC: early chick

\begin{tabular}{|c|c|c|c|}
\hline $\begin{array}{l}\text { Response variable } \\
\text { or predictor } \\
\text { variable }\end{array}$ & $\begin{array}{l}\qquad \boldsymbol{F} \text { for } \\
\text { rression or } \\
\text { dictor varia }\end{array}$ & $\begin{array}{l}\text { for } \\
\text { les }\end{array}$ & $\mathrm{R}^{2}$ \\
\hline Maximum distance & $44.2_{15,171}$ & $<0.005$ & \multirow[t]{8}{*}{0.79} \\
\hline Inc (vs. LC) & 15.33 & $<0.005$ & \\
\hline $\mathrm{EC}$ (vs. LC) & -5.36 & $<0.005$ & \\
\hline $\begin{array}{l}\text { Year }(1996-1999 \text { and } \\
2001-2006 \text { vs. } 2000)\end{array}$ & $3.73-0.06$ & $<0.005-0.95$ & \\
\hline Sex & 1.94 & 0.05 & \\
\hline Sex, excluding 3 females & 0.80 & 0.42 & \\
\hline Sex $\times$ Stage & -2.15 & 0.03 & \\
\hline $\begin{array}{l}\text { Sex } \times \text { Stage, excluding } \\
3 \text { females }\end{array}$ & -1.57 & 0.12 & \\
\hline Mean distance & $52.9_{15,171}$ & $<0.005$ & \multirow[t]{8}{*}{0.84} \\
\hline Inc (vs. LC) & 19.74 & $<0.005$ & \\
\hline $\mathrm{EC}(\mathrm{vs} . \mathrm{LC})$ & -3.21 & 0.002 & \\
\hline $\begin{array}{l}\text { Year }(1996-1999 \text { and } \\
2001-2006 \text { vs. } 2000)\end{array}$ & $2.77-0.05$ & $0.006-0.96$ & \\
\hline Sex & 1.38 & 0.17 & \\
\hline Sex, excluding 3 females & -0.51 & 0.61 & \\
\hline Sex $\times$ Stage & -2.05 & 0.04 & \\
\hline $\begin{array}{l}\text { Sex } \times \text { Stage, excluding } \\
3 \text { females }\end{array}$ & -1.31 & 0.19 & \\
\hline
\end{tabular}

\section{Variation within the breeding season}

Penguins traveled farthest during incubation (411 \pm $11.8 \mathrm{~km}, \mathrm{n}=80$ ) (Table 3, Figs. $3 \& 4$ ), and stayed closest to the colony when chicks were small (mean trip distance $=61 \pm 3.9 \mathrm{~km}$, mean maximum trip distance $=$ $92 \pm 6.5 \mathrm{~km}, \mathrm{n}=35$ ) (Fig. 5). During the late-chick period when chicks had a larger storage capacity, distances were intermediate (mean trip distance $=111 \pm$ $5.0 \mathrm{~km}$, mean maximum trip distance $=176 \pm 5.9 \mathrm{~km}$, $\mathrm{n}=101$ ) (Fig. 6). Distances among all 3 stages of the breeding season were significantly different (Table 3). The direction penguins swam from the colony, generally northeast, varied little among stages or years (Figs. 4-6). No penguins used the extensive areas south or southeast of the colony when breeding.

\section{Variation among years}

Trip distances during incubation increased from 1997 through 2002, and then declined, though not to the level of the earlier years (Table 3, Fig. 3). In the first
5 yr of tracking (1997 to 2001), 3 of 35 penguins (8.6\%) traveled more than $500 \mathrm{~km}$ (Fig. $4 \mathrm{a}-\mathrm{c}$ ). In the last $5 \mathrm{yr}$ (2002 to 2006), 13 of 45 penguins $(28.9 \%)$ traveled $>500 \mathrm{~km}(G=5.49, \mathrm{p}=0.02)$ (Fig. $4 \mathrm{~d}-\mathrm{f})$. The mean trip distance for 1997 to 2001 was $386 \pm 18.7 \mathrm{~km}$, and in 2002 to 2006 the mean trip distance increased to $431 \pm$ $14.7 \mathrm{~km}\left(t_{69}=-1.86, \mathrm{p}=0.07\right)$. In 2002, all penguins swam $>500 \mathrm{~km}$ from the colony $(\mathrm{n}=4)($ Fig. $4 \mathrm{~d})$. Two of the males that we tracked in 2002 took the first incubation shift, and therefore did not leave their nests when the transmitters were attached. Males rarely incubate first but will when females are in poor body condition (Yorio \& Boersma 1994).

Distances to foraging locations during chick rearing were variable among years but overall increased with year (Figs. 3, 5 \& 6). When chicks were small, both mean (simple linear regression: $F_{1,32}=10.83, \mathrm{p}=0.002$, $\left.\mathrm{R}^{2}=0.13\right)$ and maximum distances $\left(F_{1,32}=9.55, \mathrm{p}=\right.$ $0.004, R^{2}=0.17$ ) increased over 4 yr (Figs. $3 \& 5$ ). When chicks were older, maximum distances (simple linear regression: $F_{1,84}=5.98, \mathrm{p}=0.02, \mathrm{R}^{2}=0.07$ ), but not mean distances $\left(F_{1,84}=2.37, \mathrm{p}=0.13\right)$ increased over 11 yr (Figs. 3 \& 6).

The annual mean maximum distances during incubation, early-chick, and late-chick stages varied by factors of approximately 1.8, 1.6 and 1.9, respectively. Annual mean trip distances during early-chick and late-chick stages varied by factors of 1.5 and 1.7, respectively. However, individual trips varied more, with trip distances ranging from 94 to $605 \mathrm{~km}$ during incubation, 6 to $182 \mathrm{~km}$ during early chick, and 7 to $372 \mathrm{~km}$ during late chick (Figs. 4-6). One penguin made trips ranging from 8 to $182 \mathrm{~km}$ during early chick and another made trips ranging from 17 to $289 \mathrm{~km}$ during late chick. During incubation, the mean difference between the shortest and longest trips within years was $253 \pm 35.1 \mathrm{~km}$ (Fig. 4). The shortest difference in trip distance during incubation within a year was $69 \mathrm{~km}$ in 2002; the longest was $456 \mathrm{~km}$ in 2000. When chicks were small, the mean difference among trips within years was $137 \pm$ $19.2 \mathrm{~km}$, and when chicks were large, $241 \pm 21.5 \mathrm{~km}$ (Figs. $5 \& 6$ ).

\section{DISCUSSION}

Foraging-trip distance varied within and among years, as well as among penguins and among trips by the same penguin (Figs. 3-6). Magellanic penguins feed along fronts and in areas of high productivity (Boersma et al. in press). Many seabirds forage primarily in productive oceanographic features (Hunt et al. 1999), but some variability among years is probably the rule, as oceanographic features vary in strength 


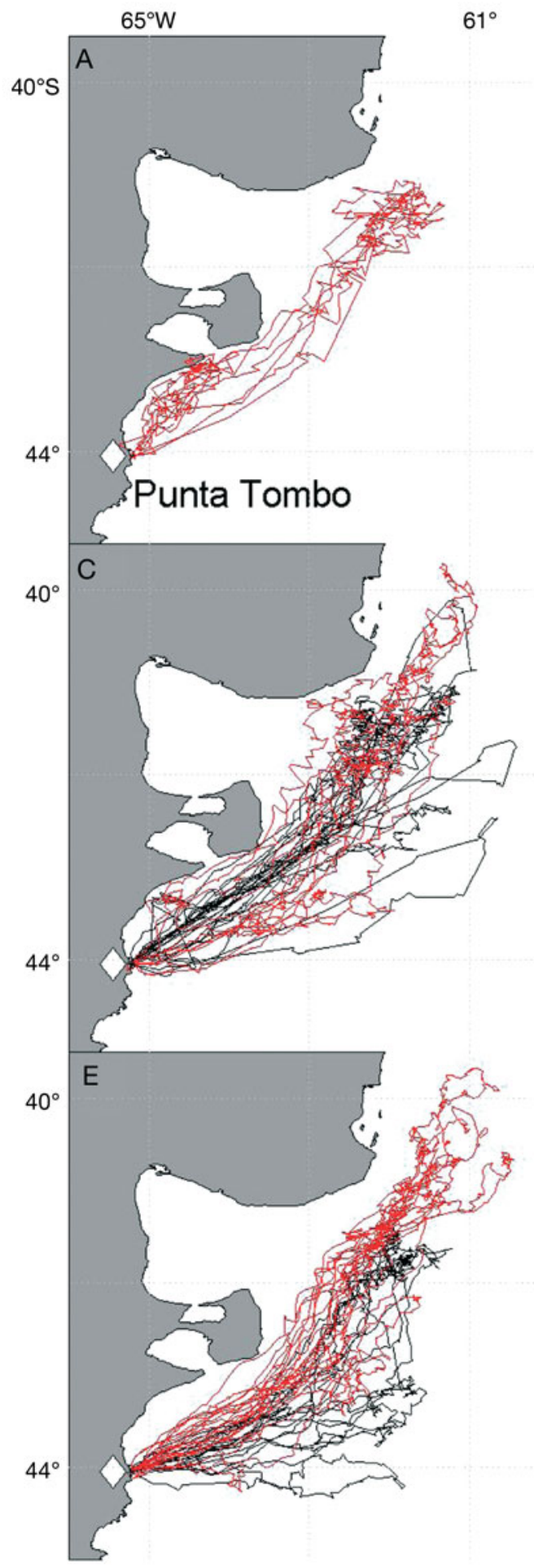

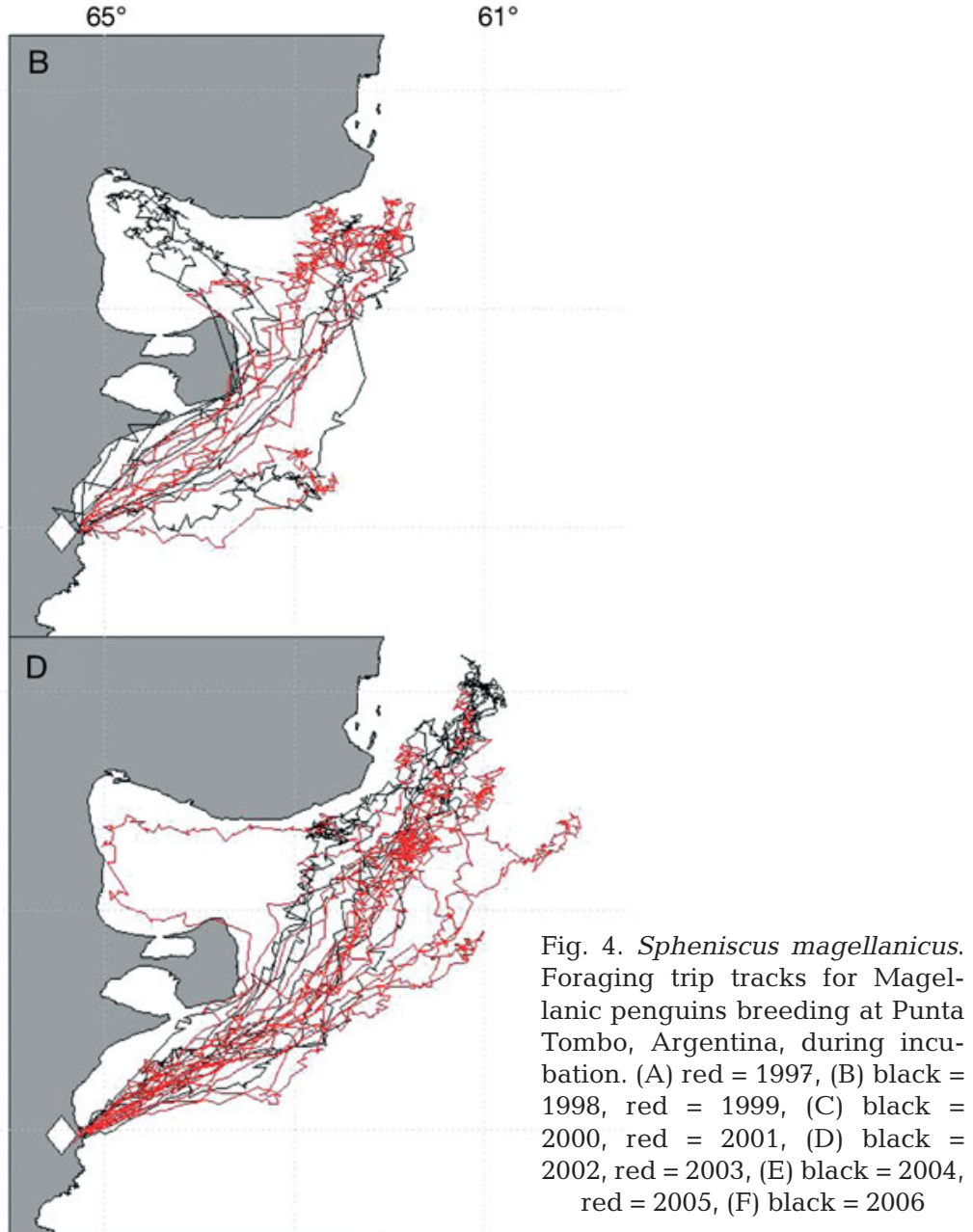

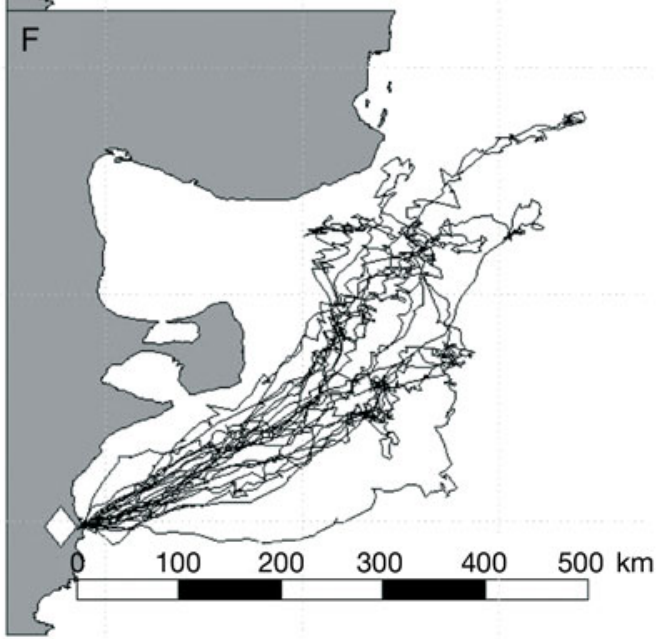

from year to year and those that are not fixed bathymetrically move. Differences in foraging-trip distance or duration within species among years are common in multi-year studies and likely reflect changes in prey availability (e.g. Kitaysky et al. 2000, Ballard et al. 2001, Boersma et al. 2002, Lescroël \& Bost 2005). Vari- ability among individuals from the same colony is probably common as well (Ballard et al. 2001), reflecting factors such as age, experience, body condition, and number and size of chicks. Variability in foraging trips among individuals and among years is seldom accounted for in modeling studies (e.g. Green et al. 


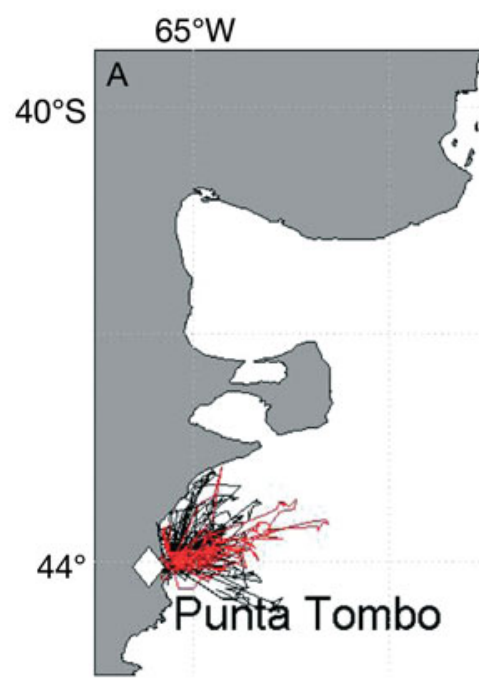

$61^{\circ}$

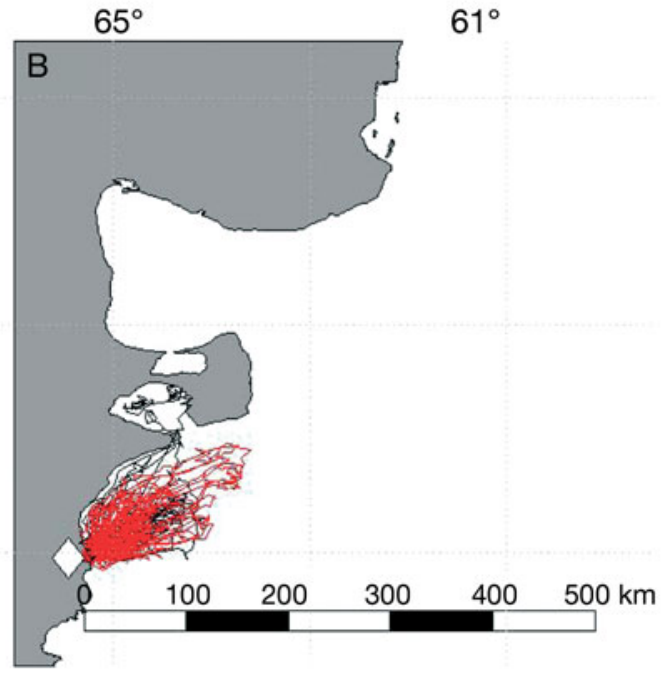

Fig. 5. Spheniscus magellanicus. Foraging trip tracks for Magellanic penguins breeding at Punta Tombo, Argentina, during early chick (chicks < 30 d old). (A) black = 1998, red = 1999, (B) black $=2000$, red $=2001$
2007), but it is large and affects adult and offspring energy balances as well as demographic parameters such as reproductive success and recruitment. It is also an important consideration for management and conservation. Marine protected areas and ocean zoning must take variability in trip distance into account to protect penguins in all their foraging areas, particularly when human and penguin uses of an area conflict.

\section{Foraging-trip distance and duration}

A positive relationship between trip distance and duration is known for several penguin species (e.g. Petersen et al. 2006, Boersma et al. 2007), but how that relationship varies is unknown. Our large dataset allowed us to refine the relationship for Magellanic penguins, and determine that it is linear during incubation and nonlinear during chick rearing. When chicks are older the relationship varies by individual penguin. Variation among penguins likely reflects luck as well as the foraging ability and experience of the individual and leads to variation in the reproductive outcome of mating pairs. The simple linear relationship between distance and duration was robust, suggesting that (1) duration is a good predictor of how far penguins travel, and (2) choice of filtering methods, at least for some analyses, may make little difference.

Penguins that traveled the farthest from the colony stayed away longer than predicted by a linear relationship. Boersma et al. (in press) found that penguins that go farther from the colony remain in the foraging area longer, probably because they need to replenish the extra energy required to swim greater distances. Our findings are consistent with this hypothesis: additional time spent in the foraging area on longer trips increases trip duration but not trip distance.

\section{Foraging-trip distance and reproductive success}

Trip distance influenced reproductive success at 2 levels. At the colony level, the mean distance penguins with satellite transmitters traveled during incubation each year was reflected in mean annual reproductive success. If a penguin is away from the nest too long during incubation, the incubating mate may abandon the eggs to forage for itself, or the chicks may hatch and starve before the foraging parent returns with food (Yorio \& Boersma 1994, Boersma \& Stokes 1995, Otley et al. 2004). During chick rearing, longer trips mean less frequent feeding of chicks, slower growth, and higher risk of starvation or low fledging weights (Davoren \& Montevecchi 2003). The major cause of mortality for Magellanic penguin chicks is starvation (Boersma \& Stokes 1995), and lone chicks grow more rapidly than chicks with siblings, suggesting that food is limited for Magellanic penguins (Boersma 1992). We did not detect a significant relationship between mean trip distance during late chick and mean colony reproductive success, perhaps because the penguins we tracked in that stage were not representative. We selected only penguins that had healthy chicks $>30 \mathrm{~d}$ old for tracking in late chick. However, the mean reproductive success in the colony included many penguins that had already lost both eggs or chicks by that time. The penguins we selected to track during late chick may have been better foragers than average, since many chicks starve before reaching 30 d (Boersma \& Stokes 1995). Reproductive 


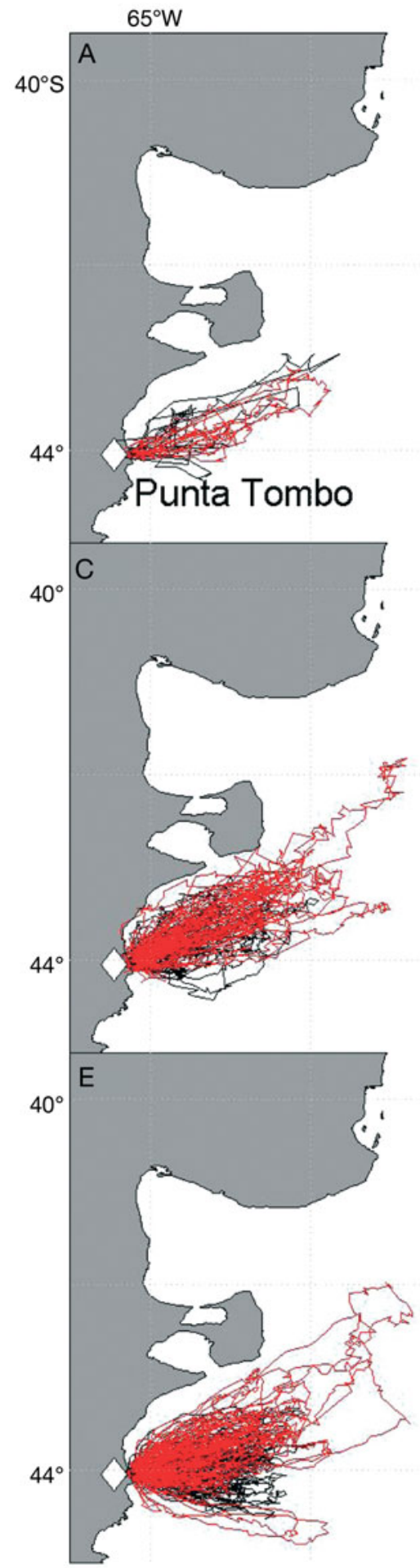

$61^{\circ}$

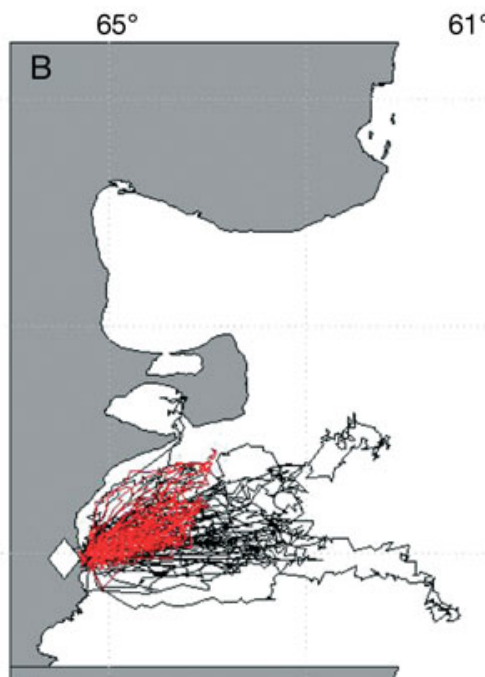

$61^{\circ}$
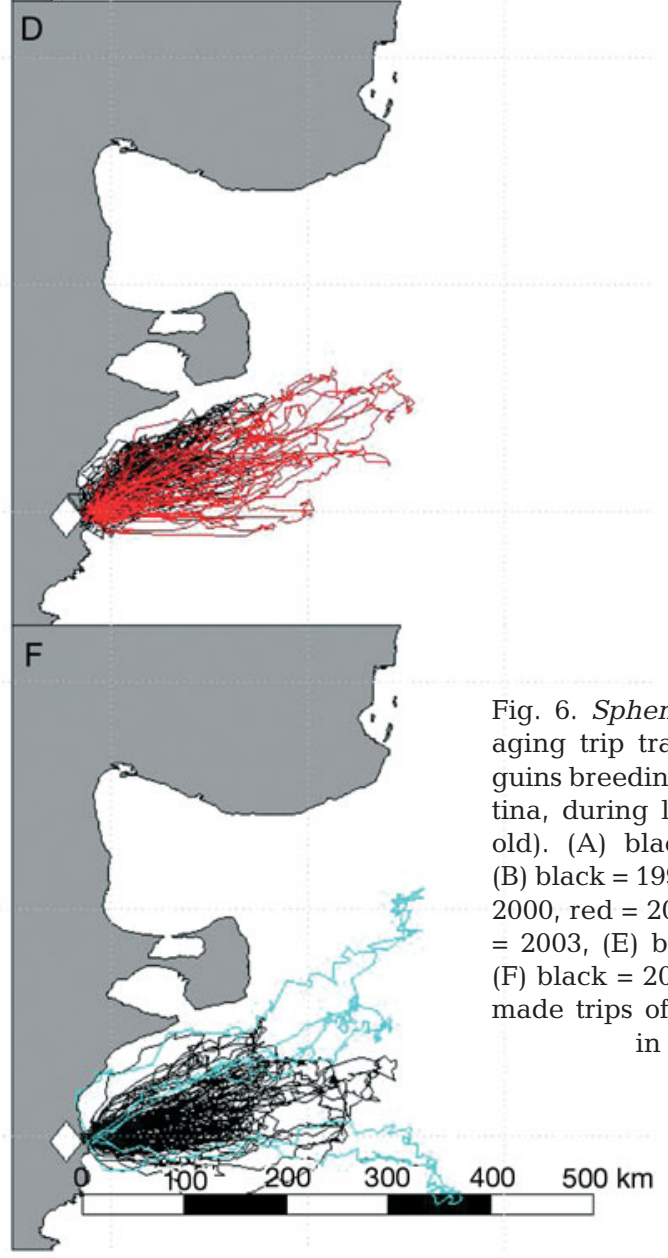

success approached one chick per nest with eggs in only one of 25 years in our long-term study of this colony, and average reproductive success is usually less than half a chick per nest with eggs (Boersma 2008).

The number of chicks fledged was negatively related to an individual's mean trip distance during late chick

(Fig. 2). Penguins that swim too far during foraging trips may not be able to deliver meals frequently enough to keep a chick alive, however, those that find food very close to the colony $(<70 \mathrm{~km})$ may fledge both chicks. Penguins that travel intermediate distances $(70$ to $180 \mathrm{~km}$ ) may be able to keep one chick alive, but not 
both. Magellanic penguins feed the larger chick more than the smaller chick (Boersma 1992), so the smaller chick may not get enough food to keep it alive until the next feeding. These data show that the average distance a penguin forages for its chicks is an important determinant of reproductive success.

During incubation and early chick there was no relationship between the number of chicks fledged and trip distance. Many eggs and young chicks were lost to predators, obscuring the relationship between trip distance and reproductive success. In addition, if chicks fledged at lighter weights when trips were longer, trip distance could have an effect on future recruitment as well as current reproduction (Mougin et al. 2000, McClung et al. 2004).

\section{Variation between sexes}

We expected males to make longer trips than females during incubation, when males are at sea earlier than females. Seasonal coastal fronts form (Rivas et al. 2006) and spawning schools of anchovy Engraulis anchoita move south (Sánchez \& de Ciechomski 1995) during this period. Hence prey may be more abundant or available farther north when males make their long incubation foraging trips and farther south when females make their trips. However, we found no evidence that females and males consistently swam different distances from the colony during any stage of the breeding season. Three females with chicks $>30 \mathrm{~d}$ old were away from their nests for 18 to $23 \mathrm{~d}$, longer than any males. We tracked about 5 times more males (84) than females (17) during late chick, but only females made these long trips. We were unable to tell if these females had abandoned their breeding attempts, but all 3 returned to their nests and their chicks were still alive when they returned. These long trips likely serve to replenish body condition and may be particularly important for females. Females are smaller than males, have a more limited storage capacity, and a less favorable surface-to-volume ratio, and hence are more likely to be in poor condition after their fast (see below) than males (Hood et al. 1998). Magellanic penguins are opportunistic foragers and prey on whatever they can find. Thus, individual differences as we found are likely more important than differences between the sexes.

\section{Variation within the breeding season}

Spawning aggregations of anchovy, a primary prey of Magellanic penguins (Frere et al. 1996, Wilson et al. 2005), are found north of Punta Tombo in October
(Sánchez \& de Ciechomski 1995). Magellanic penguin adults in good condition can fast for at least a month, allowing the foraging mate to reach these aggregations during incubation and recover weight lost during settlement, courtship, and incubation (Boersma et al. 1990). Chlorophyll a concentrations peak in November in coastal waters on the Patagonian shelf at $43^{\circ} \mathrm{S}$ (Rivas et al. 2006). By November and December, when chicks hatch and need to be fed frequently, coastal fronts have formed (Rivas et al. 2006) and anchovy aggregations are near Punta Tombo (Sánchez \& de Ciechomski 1995), allowing penguins to make much shorter trips during early chick than during incubation.

\section{Variation among years}

Variability in trip distance among years likely reflects environmental conditions and prey availability. Magellanic penguin foraging locations depend on local productivity and oceanographic fronts (Boersma et al. in press), so trip distances may reflect prey distribution and abundance. Magellanic penguins eat highly mobile pelagic prey such as anchovy that aggregate in fronts. Strength and location of fronts, and associated anchovy distributions, vary among years (Hansen et al. 2001), therefore penguin foragingtrip distances vary as well.

Penguins went farther from the colony during incubation in 2002 than in any other year. Foraging-trip distances were less variable in 2002 than in other years, in spite of having the highest mean; no penguins were able to find food close to the colony. Food was apparently scarce in 2002, as fewer penguins returned to the colony to breed, egg laying was delayed, and penguins that did breed were in poorer body condition than usual (P.D.B. unpubl. data). These factors, along with the unusual situation of males taking the first incubation shifts, indicated low food availability both prior to the breeding season and during incubation. However, during late chick 2002, penguins did not swim especially far compared to other years, indicating either that conditions had improved by January, or that penguins that still had chicks in January were very good at finding food.

Toxic algal blooms sometimes kill penguins (Shumway et al. 2003) and may also have affected the penguins in 2002. Four penguins carrying tags did not return from their incubation trips and were not seen again, suggesting they died, which is rare during the breeding season. It is possible they starved, but it seems unlikely because, in general, penguins return after their first incubation foraging trip in good condition. In 2000, 9 breeding penguins that we tracked appeared healthy right before they left on foraging 
trips; these penguins failed to return and were not seen again, coincident with a toxic algal bloom and large seabird mortality event in the region (Shumway et al. 2003). Besides the 9 penguins in 2000 and 4 in 2002, only 3 other tracked penguins failed to return from incubation trips, 2 in 1999 and one in 2001.

Since 2002, significantly more penguins traveled farther during incubation than in 1997 to 2001, suggesting changes in prey availability. In addition, trip distances during early chick increased linearly over $4 \mathrm{yr}$, and mean maximum trip distance increased over 11 yr during late chick. These longer distances may indicate a longer-term shift in prey distribution or availability reflecting climate variation.

\section{CONCLUSIONS}

Foraging distance is closely related to the time a penguin is away from the nest and is an important determinant of reproductive success. Understanding the variability in animal use of the marine environment is critical for effective management, conservation, and reserve design. Marine reserves or zones need to be large or flexible enough to meet the needs of the species of interest throughout the annual cycle and among years with different prey availability. Our data show that the ocean habitat requirements of Magellanic penguins are large and variable. Management of the South Atlantic ecosystem should take this variability into account to conserve penguins as well as other seabirds and marine mammals in the area.

Acknowledgements. The Wildlife Conservation Society, ExxonMobil Foundation, Esso Argentina, National Geographic Society, Thorne Foundation, Offield Foundation, Disney Wildlife Conservation Fund, MKCG Foundation, The Pew Charitable Trust marine fellows program, Friends of the Penguins and the Wadsworth Endowed Chair in Conservation Science supported the project. The research was carried out under a joint agreement between the Wildlife Conservation Society and the Office of Tourism, Province of Chubut, Argentina. We thank the Province of Chubut and the La Regina family for access to the penguin colony, and the many students and field volunteers who collected data over the years. S. Moore, E. Skewgar, A. Van Buren, and 3 anonymous reviewers improved the manuscript.

\section{LITERATURE CITED}

Acha EM, Mianzan HW, Guerrero RA, Favero M, Bava J (2004) Marine fronts at the continental shelves of austral South America: physical and ecological processes. J Mar Syst 44:83-105

Argos (2006) Argos user's manual. CLS, Ramonville SaintAgne, available at www.argos-system.org/manual/

Arnould JPY, Boyd IL, Speakman JR (1996) The relationship between foraging behaviour and energy expenditure in
Antarctic fur seals. J Zool Lond 239:769-782

Austin D, McMillan JI, Bowen WD (2003) A three-stage algorithm for filtering erroneous Argos satellite locations. Mar Mamm Sci 19:371-383

Ballard G, Ainley D, Ribic C, Barton K (2001) Effect of instrument attachment and other factors on foraging trip duration and nesting success of Adelie penguins. Condor 103: 481-490

Bannasch R, Wilson RP, Culick B (1994) Hydrodynamic aspects of design and attachment of a back-mounted device in penguins. J Exp Biol 194:83-96

Beauplet G, Dubroca L, Guinet C, Cherel Y, Dabin W, Gagne C, Hindell M (2004) Foraging ecology of subantarctic fur seals Arctocephalus tropicalis breeding on Amsterdam Island: seasonal changes in relation to maternal characteristics and pup growth. Mar Ecol Prog Ser 273:211-225

Boersma PD (1992) Asynchronous hatching and food allocation in the Magellanic penguin Spheniscus magellanicus. In: Bell BD (ed) Acta XX Congressus Internationalis Ornithologici Wellington, NZ. Ornithological Congress Trust Board, Christchurch, p 961-973

> Boersma PD (2008) Penguins as marine sentinels. Bioscience 58:597-607

Boersma PD, Stokes DL (1995) Mortality patterns, hatching asynchrony, and size asymmetry in Magellanic penguin (Spheniscus magellanicus) chicks. In: Dann P, Norman I, Reilly P (eds) The penguins: ecology and management. Surrey Beatty and Sons, Chipping Norton, New South Wales, p 3-25

Boersma PD, Stokes DL, Yorio PM (1990) Reproductive variability and historical change of Magellanic penguins (Spheniscus magellanicus) at Punta Tombo, Argentina. In: Davis L, Darby J (eds) Penguin biology. Academic Press, San Diego, CA, p 13-43

Boersma PD, Stokes DL, Strange IJ (2002) Applying ecology to conservation: tracking breeding penguins at New Island South Reserve, Falkland Islands. Aquat Conserv 12:63-74

> Boersma PD, Rebstock GA, Stokes DL (2004) Why penguin eggshells are thick. Auk 121:148-155

Boersma PD, Rebstock GA, Stokes DL, Majluf P (2007) Oceans apart: conservation models for two temperate penguin species shaped by the marine environment. Mar Ecol Prog Ser 335:217-225

Boersma PD, Rebstock GA, Frere E, Moore SE (in press) Following the fish: penguins and productivity in the South Atlantic. Ecol Monogr

> Boyd IL, Arnould JPY, Barton T, Croxall JP (1994) Foraging behaviour of Antarctic fur seals during periods of contrasting prey abundance. J Anim Ecol 63:703-713

Burger AE, Shaffer SA (2008) Application of tracking and data-logging technology in research and conservation of seabirds. Auk 125:253-264

Clarke J, Manly B, Kerry K, Gardner H, Franchi E, Corsolini S, Focardi S (1998) Sex differences in Adélie penguin foraging strategies. Polar Biol 20:248-258

Davoren GK, Montevecchi WA (2003) Consequences of foraging trip duration on provisioning behaviour and fledging condition of common murres Uria aalge. J Avian Biol 34: $44-53$

Frere E, Gandini P, Lichtschein V (1996) Variacion latitudinal en la dieta del pinguino de Magallanes (Spheniscus magellanicus) en la costa Patagonica, Argentina. Ornitol Neotrop 7:35-41

González-Solís J, Croxall JP, Afanasyev V (2008) Offshore spatial segregation in giant petrels Macronectes spp.: differences between species, sexes and seasons. Aquat Conserv 17:S22-S36 
Green JA, Boyd IL, Woakes AJ, Green CJ, Butler PJ (2007) Feeding, fasting and foraging success during chick rearing in macaroni penguins. Mar Ecol Prog Ser 346: 299-312

Guinet C, Koudil M, Bost CA, Durbec JP, Georges JY, Mouchot MC, Jouventin P (1997) Foraging behaviour of satellite-tracked king penguins in relation to sea-surface temperatures obtained by satellite telemetry at Crozet Archipelago, a study during three austral summers. Mar Ecol Prog Ser 150:11-20

> Hansen JE, Martos P, Madirolas A (2001) Relationship between spatial distribution of the Patagonian stock of Argentine anchovy, Engraulis anchoita, and sea temperatures during late spring to early summer. Fish Oceanogr 10:193-206

Hood LC, Boersma PD, Wingfield JC (1998) The adrenocortical response to stress in incubating Magellanic penguins (Spheniscus magellanicus). Auk 115:76-84

Humphreys EM, Wanless S, Bryant DM (2006) Stage-dependent foraging in breeding black-legged kittiwakes Rissa tridactyla: distinguishing behavioural responses to intrinsic and extrinsic factors. J Avian Biol 37:436-446

Hunt GL Jr, Mehlum F, Russell RW, Irons D, Decker MB, Becker PH (1999) Physical processes, prey abundance, and the foraging ecology of seabirds. In: Adams NJ, Slotow R (eds) 22nd International Ornithological Congress. BirdLife South Africa, Johannesburg, p 2040-2056

Inchausti P, Guinet C, Koudil M, Durbec JP and others (2003) Inter-annual variability in the breeding performance of seabirds in relation to oceanographic anomalies that affect the Crozet and the Kerguelen sectors of the Southern Ocean. J Avian Biol 34:170-176

Kitaysky AS, Hunt GL Jr, Flint EN, Rubega MA, Decker MB (2000) Resource allocation in breeding seabirds: responses to fluctuations in their food supply. Mar Ecol Prog Ser 206:283-296

> Lescroël A, Bost CA (2005) Foraging under contrasting oceanographic conditions: the gentoo penguin at Kerguelen Archipelago. Mar Ecol Prog Ser 302:245-261

Lewis S, Benvenuti S, Dall'Antonia L, Griffiths R and others (2002) Sex-specific foraging behaviour in a monomorphic seabird. Proc R Soc Lond B 269:1687-1693

Long JS, Freese J (2006) Regression models for categorical dependent variables using Stata. Stata Press, College Station, TX

- McClung MR, Seddon PJ, Massaro M, Setiawan AN (2004) Nature-based tourism impacts on yellow-eyed penguins Megadyptes antipodes: Does unregulated visitor access affect fledging weight and juvenile survival? Biol Conserv 119:279-285

McConnell BJ, Chambers C, Fedak MA (1992) Foraging ecology of southern elephant seals in relation to the bathymetry and productivity of the Southern Ocean. Antarct Sci 4:393-398

Moreno J, Yorio P, Garcia-Borboroglu P, Potti J, Villar S (2002) Health state and reproductive output in Magellanic penguins (Spheniscus magellanicus). Ethol Ecol Evol 14: 19-28

Mougin JL, Jouanin C, Roux F, Zino F (2000) Fledging weight and juvenile survival of Cory's shearwaters Calonectris diomedea on Selvagem Grande. Ringing Migr 20:107-110

Numata M, Davis LS, Renner M (2000) Prolonged foraging trips and egg desertion in little penguins (Eudyptula minor). NZ J Zool 27:277-289

Editorial responsibility: Charles Peterson,

Morehead City, North Carolina, USA
Otley HM, Clausen AP, Christie DJ, Pütz K (2004) Aspects of the breeding biology of the Magellanic penguin in the Falkland Islands. Waterbirds 27:396-405

> Petersen SL, Ryan PG, Gremillet D (2006) Is food availability limiting African penguins Spheniscus demersus at Boulders? A comparison of foraging effort at mainland and island colonies. Ibis 148:14-26

Phalan B, Phillips RA, Silk JRD, Afanasyev V and others (2007) Foraging behaviour of four albatross species by night and day. Mar Ecol Prog Ser 340:271-286

Pinaud D, Cherel Y, Weimerskirch H (2005) Effect of environmental variability on habitat selection, diet, provisioning behaviour and chick growth in yellow-nosed albatrosses. Mar Ecol Prog Ser 298:295-304

Rabe-Hesketh S, Skrondal A (2005) Multilevel and longitudinal modeling using Stata. Stata Press, College Station, TX

Reid WV, Boersma PD (1990) Parental quality and selection on egg size in the Magellanic penguin. Evolution 44: 1780-1786

> Rivas AL, Dogliotti AI, Gagliardini DA (2006) Seasonal variability in satellite-measured surface chlorophyll in the Patagonian Shelf. Cont Shelf Res 26:703-720

Ropert-Coudert Y, Wilson RP, Daunt F, Kato A (2004) Patterns of energy acquisition by a central place forager: benefits of alternating short and long foraging trips. Behav Ecol 15: 824-830

Sánchez RP, de Ciechomski JD (1995) Spawning and nursery grounds of pelagic fish species in the sea-shelf off Argentina and adjacent areas. Sci Mar 59:455-478

Shaffer SA, Costa DP, Weimerskirch H (2003) Foraging effort in relation to the constraints of reproduction in freeranging albatrosses. Funct Ecol 17:66-74

Shumway SE, Allen SM, Boersma PD (2003) Marine birds and harmful algal blooms: sporadic victims or under-reported events? Harmful Algae 2:1-17

> Sydeman WJ, Hester MM, Thayer JA, Gress F, Martin P, Buffa J (2001) Climate change, reproductive performance and diet composition of marine birds in the southern California Current system, 1969-1997. Prog Oceanogr 49: 309-329

Tveraa T, Christensen GN (2002) Body condition and parental decisions in the snow petrel (Pagodroma nivea). Auk 119: $266-270$

Walker BG, Boersma PD (2003) Diving behavior of Magellanic penguins (Spheniscus magellanicus) at Punta Tombo, Argentina. Can J Zool 81:1471-1483

Weimerskirch $\mathrm{H}$, Salamolard M, Sarrazin F, Jouventin P (1993) Foraging strategy of wandering albatrosses through the breeding season: a study using satellite telemetry. Auk 110:325-342

Weimerskirch H, Chastel O, Ackermann L, Chaurand T, Cuenot-Chaillet F, Hindermeyer X, Judas J (1994) Alternate long and short foraging trips in pelagic seabird parents. Anim Behav 47:472-476

Williams TD (1995) The penguins. Oxford University Press, Oxford

Wilson RP, Wilson MPTJ (1989) Tape: a package-attachment technique for penguins. Wildl Soc Bull 17:77-79

Wilson RP, Scolaro JA, Grémillet D, Kierspel MAM and others (2005) How do Magellanic penguins cope with variability in their access to prey? Ecol Monogr 75:379-401

Yorio P, Boersma PD (1994) Causes of nest desertion during incubation in the Magellanic penguin (Spheniscus magellanicus). Condor 96:1076-1083

Submitted: March 6, 2008; Accepted: September 19, 2008

Proofs received from author(s): December 24, 2008 